\title{
Terminologias, gradações e continuum de cor: as formas cotidianas de classificar cor e raça em uma feira de Belém ${ }^{\mathrm{i}}$
}

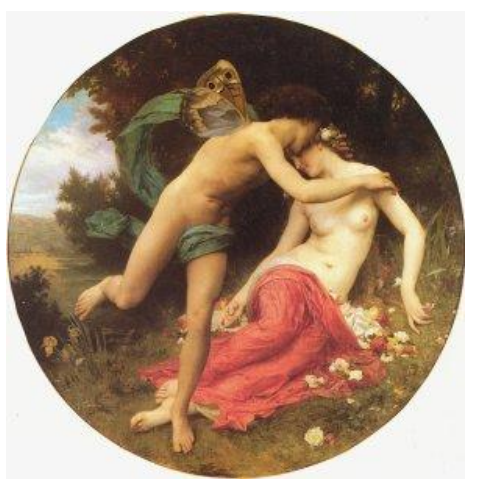

Tiago Luis Coelho Vaz, Silva ${ }^{1}$

\begin{abstract}
Resumo
Este artigo pretende discutir sobre o sistema de classificação racial brasileiro, especificamente, as formas cotidianas de pensar e classificar em termos de cor e raça. Este sistema privilegia o emprego de terminologias que seguem a lógica de um continum de cor em detrimento de termos polares, o que revela um profundo conhecimento tácito pelas pessoas das regras e dos códigos deste sistema classificatório.
\end{abstract}

Palavras-chave: Sistema de classificação racial. Continuum de cor. Gradações de cor.

\begin{abstract}
This article aims to discuss the Brazilian racial classification system, specifically, everyday ways of thinking and classifying people in terms of color and race. This system favors the use of terminologies that follow the logic of a color continum rather than polar terms, which reveals a tacit deep knowledge by the people who form the rules and codes of this classification system.
\end{abstract}

Keywords: racial classification system - Brazil; color continum; color gradations

\section{Introdução}

Neste artigo discutiremos sobre o sistema de classificação racial brasileiro, apreendendo as formas cotidianas de pensar e classificar em

\footnotetext{
1 Doutor em Ciências Sociais pela Universidade Estadual de Campinas (UNICAMP). Mestre em Antropologia Social (UFSC). Professor da Universidade do Estado do Pará (UEPA). E-mail: tvazsilva@gmail.com
} 
termos de cor e raça, através da experiência de atores sociais que constituem o cenário do mercado do Ver-o-Peso em Belém (PA). Pretende-se gerar uma interpretação sobre um sistema classificatório assentado sob a lógica que frequentemente emprega diversas terminologias que seguem o princípio de gradações e expressam um continuum de cor (moreno claro, moreno, moreno escuro, etc.) em detrimento de categorias bipolares como branco e negro.

Os termos claro, moreno, escurinho, entre outros, empregados com bastante frequência no cotidiano pelas pessoas, geralmente estão ausente da esfera acadêmica, que adota as categorias censitárias ou as expressões binárias branco/negro e branco/não branco. Tal fato demonstra uma grande dissonância entre os termos utilizados pelas pessoas no dia-a-dia e os referidos pelo movimento negro e acadêmicos em seus artigos e palestras. A aversão às categorias usadas popularmente parece dever-se ao fato das mesmas serem consideradas marcadores menos nítidos de identidade, segundo tal perspectiva, contribuindo para a desarticulação da construção de identidade étnicas que deveriam ser reforçadas.

Ora, em antropologia, aprendemos com Edmund Leach (1996) e Evans-Pritchard (2002) que devemos nos valer das categorias nativas para compreender o modo como os sujeitos constroem o seu universo de significados e não elaborar categorias analíticas para sobrepô-las. Portanto, trabalhar com outras categorias que não sejam nativas seria reduzir a complexidade dos significados atribuídos pelos indivíduos ao fenômeno, afinal a natureza do entendimento antropológico está na compreensão do ponto de vista dos nativos o seu relacionamento com a vida, a sua visão de mundo (GEERTZ, 1997; MALINOWSKI, 1978). Desconsiderar esses aspectos implica incorrer em equívoco analítico de interpretar um sistema taxonômico baseado num gradiente de cores através de terminologias extremamente formais ou expressões binárias, indo contra a própria lógica 
de organização do sistema classificatório e, consequentemente, da forma como se manifestam as relações raciais no Brasil.

Para a compreensão das formas usuais de classificação empregadas pelos interlocutores da pesquisa, adotamos a técnica de análise de discurso sobre raça, cor e racismo proposta por Robin Sheriff (2001), no intuito de contextualizar as narrativas que enfatizam a cor e as fundadas na ideia de raça. Esta técnica permitiu explorar em profundidade as informações contidas nos relatos, possibilitando uma interpretação mais segura da complexa trama pela qual se configuram os modos cotidianos de pensar e classificar em termos de cor e raça no país.

\section{A descrição na classificação da cor}

Sabe-se que o sistema de classificação racial de determinado país está intimamente relacionado à estrutura de suas relações raciais. Desde o período colonial o sistema de classificação racial brasileiro não obedece a uma lógica dual ou polarizada.

As taxonomias de cor/raça referidas neste trabalho por meus interlocutores fazem parte de um amplo processo de construção social de categorias de cor/raça no país, orientando os indivíduos na classificação de si próprios e de outras pessoas. Neste sistema classificatório privilegia-se o uso de inúmeras terminologias que seguem a lógica de gradações de cor, ao invés de categorias duais como branco e negro, o que tem sido demonstrado por estudiosos da questão (MAGGIE, 1996; SANSONE, 2003; SHERIFF, 2001).

Ao falar da cor da pele de seus filhos, uma informante descreve de maneira bastante elaborada a nuance da gradação da cor de cada um deles, constatando as suas diferentes tonalidades:

Eu tenho o meu filho mais velho, o Carlos, que é esse aí que é bem moreno, aí tem o Luís que é bem da 
minha cor, moreno claro. Tem o Guilherme que é um moreno mais claro um pouco do que o Carlos, mais escuro do que o Luís. Eles têm a cor diferente. O meu pai eu não cheguei a conhecer não. A minha mãe dizia que ele era a minha cor. (Dona Deusa, ervateira do Vero-Peso).

Esse grau de sofisticação na classificação, levando em consideração a nuance da cor da pele, o tipo de cabelo e outras características físicas, revela uma profunda consciência racial entre os brasileiros. Consciência expressa através de um elevado conhecimento fenotípico, mas que não se constitui em divisões nítidas de grupos raciais, sendo comum a ideia de que no Brasil existe apenas uma raça: a brasileira, como ouvi muitas vezes de meus informantes.

Assim, observamos que nem sempre cor e raça ${ }^{\text {ii }}$ aparecem de forma equivalente, ainda que a cor seja frequentemente utilizada para referir-se à raça e acionada para falar das diferenças sociais entre os brasileiros. No Brasil, a grande maioria das categorias não possui significação intrínseca, mas seu significado é construído na relação estabelecida com outras pessoas, tendo a ênfase incidindo sobre o fenótipo, sobretudo, na cor da pele; embora a noção de raça se faça presente de inúmeras maneiras, devido a sua fluidez e capacidade transformacional ${ }^{\text {iii }}$.

Quando meus interlocutores falam sobre a cor dos seus familiares, geralmente, eles o fazem de maneira descritiva. Seus relatos possuem como objetivo apenas a descrição das características físicas apresentadas pelos seus parentes. De acordo com Robin Sheriff (2001), nestes casos em que as pessoas precisam ou tem por intuito apenas descrever as características físicas de outras, elas fazem uso de termos de cor descritivos.

Estas classificações priorizam a descrição física dos indivíduos, não remetendo a categorias que denotem uma noção concreta de identidade racial, pois esses termos nada mais são que uma gama de classificações descritivas que levam em conta os mínimos detalhes para identificar e 
diferenciar uma pessoa de outra, a cor da pele de intensidade mais ou menos escura, por exemplo.

Em nosso sistema de classificação de cor e raça ocorre também a presença de termos agregados que enfatizam e reforçam as variadas categorias que se inserem no continum de cor. Terminologias como, bem, mesmo, mais e muito se configuram enquanto termos que ressaltam intensidade e reforço da cor/raça de quem se deseja fazer referência, uma vez que elas são pronunciadas de uma forma bem particular, com uma entonação peculiar na fala que ajuda a dar sentido e a explicar a cor/raça que se quer mencionar, auxiliando na composição da mensagem, como na descrição feita por Dona Deuza ao falar da cor dos seus filhos.

\section{Pragmatismo, negociação e contingenciamento na classificação da cor/raça}

Determinadas classificações feitas por meus informantes deixam de ser apenas descritivas para assumirem características categóricas, extremamente contingentes por se constituírem de maneira relacional. Os termos são empregados com a finalidade pragmática de categorizar as pessoas ou a si mesmo de uma forma bastante peculiar a cada indivíduo a quem se pretende fazer referência, como no caso de uma feirante que contou que sua mãe lhe considerava uma "verdadeira negra" por possuir a cor da pele clara e o cabelo "pixaim".

"É porque ela dizia que toda pessoa que é clara e tem o

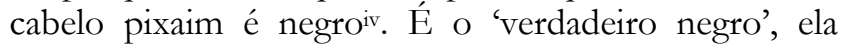
sempre dizia isso para mim (...) Aí a mamãe dizia para a gente: tu és uma verdadeira negra, sacana. O cabelo desse jeito aí, dessa cor". (Dona Deusa, ervateira do Ver-o-Peso).

De acordo com Robin Sheriff (2001), essa forma substantiva de se referir a alguém é denominada como "estilo pragmático ou indicial" de discurso cotidiano. Nesses discursos os indivíduos "manipulam 
conscientemente o vocabulário sobre raça/cor" (SHERIFF, 2001 p. 219), escolhendo uma determinada categoria racial para designar alguém, mesmo que esta não represente a "verdadeira cor" de quem se referiu, ocorrendo autonomia entre o termo usado para tratar a pessoa e o que é compreendido como a sua cor de fato.

Às vezes, o cara não é nem preto, é branco, e o apelido dele é preto. Eu tenho um sobrinho que ele é moreno e o apelido dele é 'nêgo'. Não é nem negro, é 'nêgo'. É como você ver um cara que é negrinho e o apelido dele é tapioca (Seu Davi, vendedor de farinha no Ver-oPeso).

No "estilo pragmático ou indicial" de discurso, o termo escolhido para aludir à cor/raça de alguém depende fundamentalmente "do jeito de falar", fazendo com que o indivíduo que se refere desta forma a "pessoa de cor", "marca, constrói e/ou negocia ativamente" (SHERIFF, 2001 p. 222) sua relação com esta última, podendo ofender ou não a pessoa a quem se direciona tais termos, já que são classificatórios.

No entanto, deve-se ressaltar que a própria escolha do termo a ser aplicado a alguém pode se constituir em motivo de embaraço, independentemente da maneira como ele foi proferido, caso não exista uma relação de proximidade que permita certa intimidade entre os envolvidos na situação; ou ainda, quando a pessoa não se reconhece na categoria que lhe foi atribuída, como pode ser verificado nas seguintes narrativas:

Agora, a minha cor eu sou preto, mas não sou aqueles negros. É normal o cara chamar o outro de preto: 'E preto, como é que está? '. Os colegas, mas as pessoas de fora não! (...) As pessoas me chamam de moreno. Preto é difícil de chamar, muito mais negro, negro não me chamam não! 'E moreno, como é que está?' (Seu Nato, vendedor de farinha no Ver-o-Peso).

Tem um amigo aí que a gente chama de 'negão', mas ele nem é tão escuro assim. Tem outros que tem a mão e o beiço 'roxo' e são mais escuro do que ele, só que a gente não fala assim porque não conhece, né! Outro dia 
eu vi um cara chamar um outro de 'pretinho' e ele não gostou, quase dá briga. (Carlinho, vendedor de importados e pequenos produtos no Ver-o-Peso).

É interessante observar deste primeiro relato que Seu Nato se identifica como preto, considerando comum seus parentes e amigos se referirem a ele desta forma. Mas, pessoas de fora do seu círculo de relações evitam chamá-lo de "preto" e de "negro", uma vez que não são íntimos dele. Categorias como preto, pretinho, negro, neguinho, dentre outras utilizadas para se referir a "pessoa de cor", além de dependerem do "jeito de falar" dependem, também, por quem são pronunciadas, estando sujeitas a reprovação, como no fato citado por Carlinho.

Em algumas situações os indivíduos ao mencionarem à cor de outros o fazem empregando eufemismos, substituindo categorias como preto e negro por moreno, moreno claro ou moreno escuro, como no caso de Seu Nato que é chamado de moreno por pessoas de fora do seu círculo de convivência. Os eufemismos são mais recorrentes quando se reportam às "pessoas de cor" e funcionam convencionalmente de forma tácita como uma espécie de "cortesia" ou "regra de etiqueta" social (VAN DEN BERGHE Apud CASHMORE, 2000 p. 105), sendo utilizados no intuito de suavizar termos "potencialmente ofensivos" (SHERIFF, 2001) em demonstração de respeito, para favorecer a interação entre os envolvidos.

[...] a gente sabe como as coisas funcionam por aqui [Brasil], se você tem dinheiro ou alguma posição é chamado de doutor e as coisas ficam mais fáceis. Eu nunca vi falarem pra um advogado de 'pretinho'. Só chamam o Pelé de preto quando fazem piadas dele, ainda tem isso!" (Carlinho, vendedor de importados e pequenos produtos no Ver-oPeso).

O tema sobre o qual nos fala Carlinho, vemos que a "regra de etiqueta" também funciona para "promover" por meio da classificação os indivíduos que possuem melhores condições econômicas e prestígio dentro da sociedade brasileira. Tal fato demonstra uma outra dimensão de nossas relações raciais: a classificação não leva em conta apenas as características 
físicas, mas também, atributos como o status econômico ou político, o que evidencia uma complexa correspondência entre raça e classe social. É interessante perceber como se entrelaçam classe e raça, de modo que a "cortesia" pede para não se chamar a um advogado de pretinho, neste caso prevalecendo a primeira sobre a segunda; mas quando Pelé é alcunhado de preto ocorre o inverso e a raça se sobrepõe a classe.

Desta forma, acredito que parte significativa da contingência e polissemia que norteia o nosso sistema de classificação racial esteja intimamente relacionada ao que Sheriff (2001: 222) aponta como "tentativas de evitar ou dominar, de apropriar-se ou reapropriar-se do poder profundo e difuso" da palavra negro". É, pois, nos discursos relacionados às "pessoas de cor" que a semanticidade das terminologias se confundem e passam a se constituir em eufemismos empregados retoricamente.

Assim, as categorias "negro" e "preto", que no decorrer do processo histórico e social do país foram associadas à escravidão e inferioridade racial, geralmente, são substituídas por outras que possuam conotações menos pejorativas e estigmatizantes, a não ser se a motivação for rebaixar e discriminar racialmente, como veremos no próximo tópico.

\section{Noção de Raça e Discriminação Racial na classificação}

Questão importante a ser destacada neste artigo se refere à presença nos relatos dos meus informantes o que Sheriff (2001) denominou de “estilo racial de discurso". Esta forma de discurso é construída não mais sob a ótica do continum de cor, mas sob a perspectiva de categorias raciais bipolares (branco e preto ou branco e negro) ou categorias raciais tripartites (branco, negro e mulato/ caboclo), como pode ser observado quando um feirante insatisfeito com o desempenho de seu assistente disse-lhe: "todo 'acabocado', parece que nunca trabalhou numa feira!’. A partir deste relato vemos que a categoria 'acabocado', que se origina de caboclo, exprime em 
sua essência a relação de um atributo físico a um atraso moral e intelectual, concepção pautada na ideia de raça.

Situação semelhante ocorreu quando um feirante, com um ar de jocosidade, disse a outros companheiros de profissão a respeito de um cliente que não se interessou pela sua mercadoria, quando este já estava longe e não pôde ouvir: “tinha que ser preto mesmo!", expressão tão comum de se ouvir, inclusive em anedotas e piadas. Em seguida todos se olharam, porém ninguém disse nada, talvez, devido à presença do pesquisador.

É interessante notar o posicionamento dos feirantes sobre o ocorrido, pois mesmo sabendo da existência de racismo no país, alguns deles tendo até mesmo sofrido este tipo de discriminação, evitam discussões que gerem tensão ou intensifiquem conflitos neste âmbito. No senso comum racial brasileiro, na maioria das vezes, o preconceito e a discriminação de cunho eminentemente racial não são compreendidos enquanto raciais, mas como preconceitos de classe, marcados pelos eixos simbólicos riqueza/pobreza, inclusão/exclusão; ou ainda, levados ao plano da particularização/individualidade, encarados como antipatia a uma determinada pessoa, como apontam, para este último caso, os estudos em psicologia social (GARCIA-MARQUES, 1999).

Nestes dois casos podemos perceber a ausência das múltiplas categorias que constituem o sistema classificatório brasileiro, pois estas classificações não enfatizam a cor e nem a aparência, mas ressalta não só a noção de categorias raciais, mas também a de raça.

Sabe-se que no Brasil termos como preto, negro, mulato, crioulo e outros que remetem à cor da pele (ou a raça), na maioria dos casos possuem caráter depreciativo e discriminatório que apontam para representações pautadas nas concepções de raça e, consequentemente, revelam as desigualdades entre os grupos sociais (SEYFERTH, 1995), o que pode ser constatado no anedotário sobre o negro, que constantemente 
aparecem sob disfarce de brincadeiras e uma suposta jocosidade (SEYFERTH, 1995).

Portanto, para "pretos", "morenos escuros", "escuros" e outros com a cor da pele escura, quase sempre, a palavra negro possui uma conotação pejorativa, considerada como sendo utilizada de maneira preconceituosa por pessoas racistas, como nos disse Dona Deusa: “o negro foi ditado assim pelas pessoas que são racistas. Negro é o apelido para falar do preto”. Apesar disto, nas últimas décadas o movimento negro e algumas pessoas intelectualizadas vêm buscando um processo de valorização desta categoria.

Livio Sansone (1996), pensando na noção de habitus proposta por Pierre Bourdieu (1980), acredita haver no Brasil uma série de relações construídas sob um conjunto de regras preestabelecidas em que existe um problemático consenso, o qual ele denomina habitus racial. Segundo ele, temos:

(...) um sistema racial não polar, caracterizado por um alto grau de miscigenação; uma tradição sincrética no campo da religião e cultura popular; um continuum de cor e uma norma somática que tem historicamente colocado os fenótipos negros na escala inferior da noção de 'boa aparência'. Em torno desse sistema, como produto da tradição das relações raciais, tem-se construído um conjunto de regras sobre as quais existe um certo e problemático consenso, o qual podemos chamar de habitus racial (SANSONE, 1996 p. 207).

Inspirado em Bourdieu, O habitus racial mencionado por Sansone funciona como disposições que são internalizadas, porém não se constituem em estruturas estruturadas e sim em estruturas estruturantes que persistem historicamente e tendem a reproduzir-se nas representações e práticas dos agentes sociais por meio do processo de socialização.

Para finalizar, é necessário apontar que, embora componha um gradiente de cores, as categorias estão dispostas hierarquicamente de forma 
verticalizada e não igualitariamente como poderia se pensar, por se tratar de um continuum.

Desta forma, no cume do nosso continuum de cor o termo branco surge com maior prestígio nas classificações, dito de outro modo: de maneira geral, quanto mais próximo da branquidade e distante da negritude, melhor para se incluir; pois no culto aos morenos estão excluídos aqueles de tez escura. A morenidade aparece como intermediária, uma forma que a sociedade brasileira encontrou para lidar com as questões raciais sem abordar diretamente as oposições; enquanto o termo negro ocupa o mais baixo nível da escala. Assim, vemos refletido em nosso sistema classificatório a estrutura de relações raciais do país.

\section{Em conclusão}

Menos que elaborar uma teoria a respeito de códigos e regras de funcionamento do modo como os brasileiros pensam e classificam em termos de cor e raça, procurei mostrar e discutir através de dados etnográficos o altíssimo grau de complexidade que constitui o sistema de classificação racial no país.

Como tentei demonstrar neste artigo, para a compreensão das formas usuais de classificação racial no Brasil é imprescindível contextualizar as narrativas que enfatizam a cor e as fundadas na ideia de raça. A análise de discursos sobre raça, cor e racismo (SHERIFF, 2001) permitiu explorar em profundidade as informações contidas nos relatos, de onde se constatou o elevado grau de consciência racial entre os brasileiros, expresso através da elaboração de complexas classificações no plano fenotípico.

Vimos que as classificações no país não se limitam a descrições fenotípicas. Ao extrapolar as características físicas dos indivíduos, as classificações assumem uma forma substantiva de categorização 
empregada, geralmente, por meio de terminologias retóricas, através das quais se manipula pragmaticamente a informação sobre cor ou raça. Devido à sutileza e imprecisão na maneira como se manifesta, a dimensão retórica do nosso sistema classificatório revela um emaranhado jogo que demonstra um profundo conhecimento tácito de suas regras e códigos pelas pessoas, o que afasta qualquer suposição de falta de consciência racial entre os brasileiros.

Resumidamente, podemos dizer que as classificações sobre cor e raça no Brasil, frequentemente, aparecem no discurso cotidiano sem polarizações, apresentando inúmeras terminologias e gradações de cor que, na maioria das vezes, são utilizadas de forma relacional e contextual dependendo, fundamentalmente, de onde se fala, de quem se fala, com quem se fala e a forma como se pronunciam tais termos, uma vez que o sentido das classificações emergem das experiências narradas e não dos termos empregados.

Além disso, neste sistema classificatório leva-se em consideração não só a aparência física, mas também a posição social ocupada pelo indivíduo - onde um advogado pode ser classificado como moreno ou, de outro modo, como negro, porém dificilmente como "pretinho" - existindo uma forte correlação entre raça e classe social, o que por outro lado caracteriza este sistema como relacional, constituído de contingência e polissemia, daí resulta a sua complexidade.

i Este artigo é uma versão resumida de um capítulo da dissertação de mestrado intitulada "Ver-a-cor: um estudo sobre as relações raciais no mercado do Ver-oPeso em Belém (PA)".

ii Neste trabalho o termo raça é abordado como uma categoria êmica (nativa), possuindo muitas significações e empregado de diferentes maneiras pelas pessoas.

iii As transformações e os vários sentidos atribuídos à ideia de raça ao longo da história podem ser verificados em Michael Banton (1972). 
iv A partir do relato podemos perceber que o fato de ser "clara" não implica que Dona Deusa seja branca. Portanto, claro e branco são termos que podem se apresentar como diferentes em relação a informação sobre a cor dos indivíduos.

v O mesmo tende a ocorrer com a expressão "preto", já que negro e preto aparecem muitas vezes de maneira equivalente nos discursos sobre cor/raça, embora sejam utilizados de forma diferente no que se refere a autoclassificação, como indicam as pesquisas de Sansone (2003) em dois bairros da região metropolitana de Salvador-BA.

\section{Referências}

BANTON, Michael. A ideia de raça. Lisboa: Martins Fontes, 1972.

BOURDIEU, Pierre. Le sens pratique. Paris: Les Éditions de Minuit, 1980.

CASHMORE, Ellis. Dicionário de relações étnicas e raciais. São Paulo: Summus, 2000.

EVANS-PRITCHARD, E.E. Antropologia Social. Lisboa: Edições 70, 2002.

GARCIA-MARQUES, Leonel. O estudo dos estereótipos e as novas análises do racismo. Serão os efeitos dos estereótipos inevitáveis?. In: VALA, Jorge (Org). Novos Racismos. Perspectivas Comparativas. Oeiras: Celta Editora, 1999.

GEERTZ, Clifford. "Do ponto de vista dos nativos": a natureza do entendimento antropológico. In:__. O saber local: novos ensaios em antropologia interpretativa. Petrópolis, RJ: Vozes, 1997.

LEACH, Edmund Ronald. Sistemas Politicos da Alta Birmânia: um estudo da estrutura social Kachin. São Paulo: EDUSP, 1996.

MAGGIE, Yvonne. Aqueles a quem foi negada a cor do dia: as categorias de cor e raça na cultura brasileira. In: MAIO, Marcos C.; SANTOS, Ricardo V. (orgs). Raça, ciência e sociedade. Rio de Janeiro: Fiocruz/ Centro Cultural Banco do Brasil, 1996.

MALINOWSKI, Bronislaw. Os Argonautas do Pacífico Ocidental. (Coleção os Pensadores). São Paulo: Abril Cultural, 1978.

SANSONE, Livio. Negritude sem Etnicidade: o local e o global nas relações raciais e na produção cultural negra no Brasil. Salvador/ Rio de Janeiro: Pallas, 2003.

- As relações raciais em Casa-Grande \& Senzala revisitadas à luz do processo de internacionalização e globalização. In: MAIO, Marcos C.; 
SANTOS, Ricardo V. (orgs), Raça, ciência e sociedade. Rio de Janeiro: Fiocruz/ Centro Cultural Banco do Brasil, 1996.

SEYFERTH, Giralda. A invencão da raça e o poder discricionário dos estereótipos. In: Anuário Antropológico/ 93. Rio de janeiro: Tempo Brasileiro, 1995.

SHERIFF, Robin E. Como os senhores chamavam os escravos: discurso sobre cor, raça e racismo num morro carioca. In: REZENDE, C. B.; MAGGIE, Y. (orgs), Raça como retórica: a construção da diferença. Rio de Janeiro: Civilização Brasileira, 2001. 